\title{
Autopistas, ciudadanía y democratización: la Costanera Norte y el Acceso Sur, Santiago de Chile (1997-2007) ${ }^{1}$
}

Lake Sagaris. Pontificia Universidad Católica de Chile, Santiago, Chile. Paulette Landon. Universidad Alberto Hurtado, Santiago, Chile.

RESUMEN | Después de cuarenta años de planificación centrada en el automóvil, en los países desarrollados la literatura muestra los extensos impactos que han tenido algunos movimientos ciudadanos contra las autopistas, tanto en los sistemas urbanos como en sus respectivos sistemas de planificación. Más recientemente se ha visto cómo estos modelos se propagan por el mundo, haciendo de la movilidad basada en el automóvil el paradigma central de la planificación, pese a mayoritarias opciones por el transporte público, la caminata y la bicicleta. En este estudio comparamos dos conflictos contra autopistas en la Región Metropolitana de Santiago, Chile. Identificamos una clara disposición ciudadana a luchar por aquellos derechos democráticos asociados a la emergencia de un nuevo urbanismo. Al mismo tiempo, se ve un Estado que, lejos de velar por la igualdad y los derechos de la ciudadanía, aprovecha las desventajas de algunas comunidades, imponiendo inversiones que empeoran sus condiciones de vida y sus posibilidades de integración, en algunos casos dramáticamente.

PALABRAS CLAVE | conflicto social, planificación urbana, transporte urbano.

ABSTRACT | After forty years of car-centered planning, developed countries have generated a convincing body of evidence that reveals the extensive impacts of citizen movements against highways, in terms of both urban and planning systems. More recently, we have seen these models expand worldwide, turning auto mobility into the dominant planning paradigm, despite majority modal shares for walking, cycling and public transit. In this study, we compare two such anti-highway revolts in metropolitan Santiago, Chile. We find citizens determined to defend their democratic rights, associated with the emergence of a new urbanism. At the same time, instead of guaranteeing equality and citizen rights, particularly to those most vulnerable, the government takes advantage of some communities, imposing investments that far from improving their integration, actually reduces it, sometimes dramatically.

KEYWORDS | social conflict, urban planning, transportation.

1 La investigación doctoral y posdoctoral de la Dra. Sagaris recibió el apoyo del Social Science and Humanities Research Council, de Canadá, y del Centro de Estudios de Desarrollo Urbano Sustentable (cedeus), de la Pontificia Universidad Católica de Chile, con financiamiento de CONICYT, FONDAP n. ${ }^{\circ} 15110020$, junto con el Centro de Excelencia en Transporte Rápido en Buses - Across Latitudes and Cultures. La investigación doctoral de P. Landon, PhD (c), fue financiada por CONICYT Chile. 


\section{Introducción}

Transcurridos cuarenta años de los conflictos relacionados con la construcción de autopistas urbanas en ciudades de Europa, Canadá y Estados Unidos, la literatura muestra los extensos impactos que ellos tuvieron tanto en los sistemas de planificación urbana como en los sistemas urbanos en sí mismos. En ciudades tan diversas como Toronto, Ámsterdam, Nueva York, Portland y Vancouver, fomentaron políticas más favorables al transporte público, la bicicleta y la caminata. También influyeron en los sistemas de participación, que fueron evolucionando en tres modalidades: "paternalistas", "de conflicto" o "de colaboración/coproducción”, como se constató en estudios de la época (Susskind \& Elliott, 1983).

Más recientemente, también en países en desarrollo se ha visto la imposición de modelos urbanos importados y, con ellos, su enfoque en una planificación urbana centrada en el automóvil. Ampliamente estudiada, esta modalidad se condensa en el concepto de "automovilidad" (Sheller \& Urry, 2000), que subraya la fuerza del automóvil como un artefacto a la vez económico y sociocultural. Poco se sabe, sin embargo, sobre la forma en que estas tendencias se expresan en conflictos urbanos y qué impactos tienen en la ciudad, la planificación y la sociedad en su conjunto, en los países en desarrollo. ¿Desempeñan un rol en recalibrar los desequilibrios del poder? ¿Ayudan a producir nuevas formas de planificar? Y si es así, estas nuevas formas ¿`son más favorables a resultados sustentables, en términos no solo económicos y ambientales, sino también sociales? ¿Qué significa "sustentabilidad social" cuando aplicamos este concepto hoy?

Buscamos respuestas a estas preguntas a través de una exploración de las similitudes y los contrastes entre dos conflictos recientes, ambos relacionados con autopistas, en Santiago de Chile. Tanto en el movimiento ciudadano Coordinadora No a la Costanera Norte, como en los múltiples actos de resistencia a la autopista Acceso Sur, la ciudadanía se opuso a la implantación inconsulta de autopistas urbanas, con diversos resultados en cuanto a ciudadanía, ciudad y planificación. Este artículo explora estas materias, observando diferencias sustanciales en los efectos finales de ambos proyectos, que repercuten de forma grave en la exclusión y la vulnerabilidad versus la inclusión, la equidad y, por sobre todo, la igualdad en los derechos de distintas comunidades urbanas.

Las coautoras venimos de las ciencias sociales, específicamente de la planificación urbana y el trabajo social. Como escritora y luego planificadora urbana (pos 2006), una ocupa una metodología cualitativa con elementos de la teoría de la complejidad (Byrne, 2001), coherente con los temas y sus actores. Trabaja con métodos de investigación participativa (Reason \& Bradbury, 2008) para construir una narrativa colectiva de la experiencia de la campańa contra la Costanera Norte, y luego explora elementos clave de este proceso, relacionados con la formación de ciudadanía y sociedad civil, el ejercicio del poder, y una gestión urbana más colaborativa e integral.

La otra, como cientista y trabajadora social, aborda el tema mediante un enfoque metodológico cualitativo, exploratorio y descriptivo en el sentido de Orlikowski y Baroudi (1991), cuyo propósito es entender cómo los miembros de un grupo social, a través de su participación en procesos sociales, establecen sus realidades 
particulares y las dotan de significado (Reyes \& Hernández, 2008, p. 8). Usa el estudio de casos como estrategia microsocial, que permite profundizar en las características del proceso de instalación y puesta en marcha de la Autopista Acceso Sur, y sus implicancias en la movilidad y vida cotidiana de los habitantes de los barrios aledaños, ubicados en las comunas de La Granja, La Pintana y Puente Alto de la Región Metropolitana (RM) de Santiago.

Para recoger datos, validar observaciones y definir conclusiones, se usaron entrevistas con informantes seleccionados por su representatividad en los temas de interés, observación en terreno y talleres de reflexión con los afectados.

Los estudios doctorales impusieron exigencias de método y de rigor en este trabajo, pero también aportaron los recursos para exploraciones a fondo que son poco comunes para temas de ciudadanía y sociedad civil en nuestro medio. Esto significó poder capturar, en el caso de la Coordinadora/Ciudad Viva, fenómenos que probablemente concurren en situaciones afines, pero que pocas veces son estudiadas a fondo: el rol de la ciudadanía en la democratización y la innovación, la importancia de organizaciones y otros colectivos, y la potencialidad de una política de comunicaciones personalizada y creativa frente a la censura y el sesgo imperante.

En el caso del Acceso Sur, la investigación permitió, a través de los discursos de los distintos actores involucrados, identificar las reacciones frente a un proyecto vial que no consideró la participación de los residentes de los barrios intervenidos, y comprender los sentidos y efectos de dichas reacciones según el nivel de poder de los actores involucrados y los diversos intereses en juego.

Esta reflexión abre la discusión sobre la necesidad de contar con una instancia de coordinación metropolitana que garantice, con canales institucionales claros, el derecho de la ciudadanía a participar, tanto para resolver los problemas urbanos como para asegurar la consideración de factores sociales, medioambientales y de vulnerabilidad.

En la siguiente sección se presenta un resumen de los estudios sobre los movimientos ciudadanos antiautopistas en países desarrollados, donde se examina temas de democratización y ciudadanía, además de sus efectos en la ciudad y sistemas de planificación/participación. En la tercera sección se examina el caso de la Costanera Norte, y en la cuarta, el del Acceso Sur. A continuación se resumen algunas observaciones que surgen al comparar los dos casos, para cerrar con algunas reflexiones finales.

\section{Autopistas y democratización: los movimientos ciudadanos del siglo $\mathrm{xx}$ y sus impactos}

A fines de los años setenta comenzó una serie de movimientos urbanos en Canadá, EE.UU. y Europa, frente a desafíos de la participación ciudadana en la gestión urbana. Hoy, cuarenta años después, una convincente literatura demuestra los extensos impactos que tuvieron algunos conflictos relacionados con autopistas urbanas (Susskind \& Elliott, 1983). Aparecen, además, conflictos similares en países en desarrollo (Hasan, 2005).

En el caso de los países desarrollados, Tilly (2007) destaca el hecho de que se trata de democracias fruto del período de posguerra, cuando se dio una integración 
plena de mujeres, personas de distintas razas y personas no propietarias dentro del electorado. Desde entonces, las ciencias sociales son testigo de avances significativos no solo en cuanto a la práctica de la democracia representativa, sino también de culturas democráticas basadas en una participación significativa y diversa de la ciudadanía. Además, se comenzó a considerar en este escenario no solo a los gobiernos, sino la "gobernanza", vale decir, el proceso de gobernar y gestionar los territorios y las políticas públicas, que involucra no solo las fuerzas políticas estatales sino también a los privados y la ciudadanía, sea esto dentro de marcos clientelistas o de ciudadanía "activa" -temas explorados en más detalle en la siguiente sección-. Un elemento importante en esta perspectiva es la "sociedad civil", o sea, las organizaciones de la ciudadanía (Barber, 1998), como actores líderes. Esta mirada, donde las actividades ciudadanas dejan de responder a patrones clientelistas para trasladarse a un marco de acción y exigencias con base en los derechos, considera que el Estado tiene un rol fundamental como distribuidor de los bienes de la sociedad, garante de la justicia social y, por lo tanto, de la igualdad en el ejercicio de los derechos ciudadanos (Fainstein, 2010; Friedmann, 1992; Tilly, 2007; entre otros).

Evans (2002) complejiza el tema en diversos estudios realizados en países en desarrollo que demuestran la importancia de las interacciones entre distintos actores públicos, ciudadanos y privados, para lograr cambios significativos a favor de la equidad. La sociedad civil no es tan efectiva actuando sola, sino cuando forma parte de y moviliza a una "ecología" de actores sociopolíticos, capaces de levantar nuevos temas, desafiar leyes y reglas discriminatorias y permitir el desarrollo de cambios, e incluso nuevos paradigmas, en cuanto a los imaginarios sociales de distintos países y ciudades.

Tilly (2007) enfatiza que lejos de ser lineales, los procesos de democratización avanzan y retroceden, amenazados por la desdemocratización e incluso por períodos francamente antidemocráticos. En un estudio fundamental sobre estos temas, identifica tres elementos vitales para reforzar la democracia, entre los cuales la "institucionalidad representativa” es solo un comienzo. Es esencial, agrega, abarcar y eliminar la "discriminación categórica", sea por sexo, raza, nivel socioeconómico u otros motivos, y también contrarrestar los "clústeres autónomos de poder", lo que en Chile se conoce como "poderes fácticos".

Desde América Latina, Avritzer (2002) identifica la importancia del espacio local para un proyecto de democratización general. Observa que en nuestro continente es imposible depender solo de las elites políticas para profundizar las democracias. A partir de experiencias en Brasil, subraya la importancia de la deliberación cara a cara, la libertad de expresión y asociación, y el rol que cumplen movimientos sociales y asociaciones voluntarias en levantar temas novedosos que desafíen el quehacer habitual de la sociedad. Las organizaciones a nivel urbano expresan la emergencia de nuevos valores basados en la autonomía y, según algunos estudios, forman ciudadanos más comprometidos con los valores democráticos.

Así, distintos pensadores identifican la importancia no solo de la democratización, sino también del rol de un nuevo tipo de ciudadanía, para revertir tradiciones favorables a modelos autoritarios y clientelistas y reforzar las tendencias necesarias 
para brindar cierta igualdad a la ciudadanía, más allá de las pequeñas minorías privilegiadas.

Para que esto ocurra, el marco de las reivindicaciones también se debe redibujar, pasando de la negociación de privilegios a cambio de apoyo político (el clientelismo) a una reclamación de derechos fundamentales (Taylor, 2004). En este sentido, primero Lefebvre (Lefebvre \& Goonewardena, 2008) y más recientemente Borja (2002) y Harvey (2012) hablan del "derecho a la ciudad", que reconoce que "la ciudadanía se origina en las ciudades" y que "sin instituciones fuertes y representativas no hay ciudadanía” (Borja, 2002, p. 7). Para este estudio consideramos importante que estas instituciones garanticen equidad en el ejercicio de los derechos ciudadanos, particularmente en cuanto a la participación en la planificación urbana-regional.

Desde esta perspectiva, el derecho a la ciudad es de "cuarta generación": nace como resultado de las luchas por los derechos civiles (siglo XVIII), políticos (siglo XIX) y sociales (siglo xx). Es un derecho colectivo (Sorensen \& Sagaris, 2010), compuesto de una serie de derechos que son "evolutivos", o sea, avanzan con los logros y las nuevas exigencias que nacen, fundamentalmente, de nuevas organizaciones y movimientos de la sociedad civil (Borja, 2002, pp. 8-10).

Las luchas sociales asociadas a la gestión urbana y territorial, por lo tanto, tienen importancia por sus impactos locales, pero también por lo que pueden aportar a la democratización general de las ciudades y sociedades donde ocurren. No solo son importantes los movimientos sociales que ocurren en las ciudades como manifestaciones acotadas, sino que también es relevante su potencialidad de convertirse en organizaciones de largo aliento, que acumulan conocimientos, credibilidad y capacidad de acción; de crear nuevas formas, más inclusivas y democráticas; y de diseñar, actuar y convivir.

En relación con la habilidad de actuar ciudadanamente, Dahl (1992) pregunta de dónde viene la competencia individual. Esta ha sido un tema de interés desde los años setenta, primero en trabajos clásicos de Pateman (1974) y Mansbridge (1983), para luego evolucionar hacia las teorías y prácticas relacionadas con la "profundización” de la democracia (Gastil, 2000). De forma similar, la capacidad de realizar acciones colectivas efectivamente, a través de organizaciones ciudadanas (sociedad civil), es examinada por Barber (1998), quien la considera la esencia de la democracia. Putnam (2000) atribuye esta capacidad de actuar colectivamente a lo que él llama "capital social”, distinguiendo entre dos tipos: de "apego" (bonding), entre personas similares, por ejemplo de la misma religión u origen étnico; y de "puente" (bridging), entre personas diferentes.

En la esfera de la planificación, mientras tanto, Booher e Innes (2002) destacan tres factores vitales para formar lazos de confianza e influir en el uso del poder: la "diversidad" de los actores convocados, que se relaciona directamente con el capital social de puente definido por Putnam; la colaboración a pesar de las diferencias, que llaman "interdependencia"; y un método basado en la deliberación, que llaman "diálogo auténtico".

Desde los años ochenta, algunos estudios revelan cómo las luchas ciudadanas contra autopistas y otros temas afines crearon un aprendizaje de ciudadanía 
importante (Susskind \& Elliott, 1983), basado justamente en las condiciones identificadas por Booher e Innes. De la rebeldía ciudadana frente a proyectos urbanos, nacen nuevas formas de planificar y nuevos modelos de ciudad. En cuanto a los procesos, se destaca la importancia de la colaboración basada en la deliberación entre actores diversos; y en cuanto a sus resultados, el desarrollo de modos alternativos al automóvil.

Un caso al respecto es el que tuvo lugar en la década de 1970 en Holanda, donde nació un movimiento contra los automovilistas que causaban muertes y discapacidades, el que derivó en tres décadas de intensa actividad a favor de una planificación urbana que peatoniza áreas importantes de la ciudad e integra la bicicleta como modo esencial para viajes de uno a cinco kilómetros (Wagenbuur, 2009). Por su parte, en América del Norte se originaron "revueltas" contra el imperio del automóvil que se comenzó a instalar en la suburbanización de posguerra (Jacobs, 1961). Hasta hoy, algunas ciudades reflejan los alcances de estas campañas ciudadanas, que construyeron nuevas formas de hacer ciudad. Nueva York y Toronto (Jacobs, 1961), por ejemplo, gozan de niveles de transporte público significativamente mayores que otras ciudades. Vancouver y Portland, donde los movimientos ciudadanos fueron particularmente efectivos, son excepcionales en cuanto al uso de la planificación urbana para responder a los anhelos de los vecinos, priorizando la belleza (Vancouver) y la integralidad del transporte con el uso del suelo, la democratización y diversas prácticas participativas (Portland), condiciones que les han otorgado un creciente reconocimiento internacional (Thomson, 2001).

No obstante el peso de esta evidencia, poco sabemos sobre cómo estos conflictos urbanos influyen en los procesos de planificación y sus resultados en la ciudad, cuando surgen en países en desarrollo y en el contexto de una democratización mucho más reciente.

El impacto en Chile de una dictadura militar (1973-1990) revela cómo se reforzó una elite económica, política y social que sigue ejerciendo una influencia desproporcionada en todo ámbito (Délano \& Traslaviña, 1989; Matamala, 2015). Los niveles de confianza en Chile, mientras tanto, se encuentran entre los más bajos de América Latina y del mundo (Latinobarómetro, 2004). La segregación de la ciudad (Sabatini, Wormald, Sierralta \& Peters, 2009) milita en contra del encuentro entre personas diversas, aunque existen algunas zonas excepcionales, como veremos en estos casos. Y desde miradas múltiples, Chile es reconocido como uno de los países más desiguales en el mundo (Bradford, 2011), una situación que refleja una discriminación asociada a lo que Tilly (2007) identifica como la "desigualdad de categoría”. De hecho, un estudio del Programa de las Naciones Unidas para el Desarrollo (PNUD, 2004) arrojó niveles de discriminación en Chile por motivos socioeconómicos, mayores a la discriminación por género y raza en Estados Unidos, el Reino Unido y Canadá, todos países con reconocidos desafíos en este sentido.

Como demuestra Tilly (2007), la persistencia de poderes fácticos que controlan importantes decisiones y recursos de formas no transparentes, la desigualdad que nace de la discriminación y la falta de confianza, no solo son problemas de gestión en el país, sino que, además, son amenazas a una democratización relativamente nueva después del trauma de la dictadura. Estas son condiciones muy distintas a las 
que generaron los movimientos antiautopistas en EE.uU., Canadá y Europa durante los años setenta y ochenta. ¿Cómo, entonces, podemos leer estas experiencias a la luz de la experiencia internacional, pero también de la realidad chilena?

Al nivel de ciudadanía, es clara la importancia de moverse desde posiciones de clientelismo y una ciudadanía referida solo al consumo, identificadas por varios estudiosos de Chile (Taylor, 2004; Oxhorn, 2009), hacia actitudes de autonomía que permitan oposición, pero también proposición y colaboración. En este sentido, no solo son importantes los movimientos sociales, sino también su capacidad de crear organizaciones ciudadanas de mayor continuidad.

En esta comparación de dos conflictos a raíz de proyectos de autopistas en Santiago de Chile, se verán algunos de los logros de una ciudadanía que se organiza para incidir en las políticas urbanas. También las limitaciones, cuando esta participación no se integra plenamente a la institucionalidad, y particularmente a la gobernanza urbana y regional. Estos casos grafican que incluso institucionalidades imperfectas, como el Sistema de Evaluación de Impacto Ambiental (sEIA) en Chile, son importantes a la hora de crear modos de participación que aporten tanto a la planificación como a culturas más inclusivas.

Como ilustran ambos casos presentados, la Costanera Norte y el Acceso Sur, en estas decisiones sobre proyectos de autopista están en juego derechos humanos fundamentales para una gestión territorial democrática. Difícilmente podemos aspirar a una sustentabilidad económica o ambiental si no le damos prioridad a la sustentabilidad social, ofreciendo respuestas justas a las necesidades y aspiraciones de las personas y sus comunidades.

\section{Escuela de ciudadanía: la Coordinadora No a la Costanera Norte}

\section{El proyecto Costanera Norte}

La autopista concesionada Costanera Norte fue objeto del primer conflicto mayor relacionado con una política urbana en el Chile pos-Pinochet. En 1993, las juntas de vecinos se habían reconstituido democráticamente y los gobiernos locales municipales también renovaban sus autoridades a través de elecciones. En estas condiciones, en 1996-1997 el Ministerio de Obras Públicas (MOP), liderado por Ricardo Lagos, anunció su primera autopista urbana, la Costanera Norte. Inicialmente, el proyecto de 33 kilómetros que se extendía entre los barrios de altos ingresos en el oriente de la ciudad, el centro y los servicios portuarios, balnearios, aeropuerto y otros, por el occidente (figura 1), iba a costar USD 143 millones, precio que fue subiendo al avanzar los cuestionamientos al proyecto. A pesar de su alto costo en calidad urbana y en recursos estatales y privados, el proyecto no resolvía problemas de segregación y de transporte de la mayoría de la población, sin acceso al automóvil.

A pesar de haber prometido que el proyecto entraría al Sistema de Evaluación de Impacto Ambiental (sEIA), entonces muy nuevo, de hecho irrumpió en la prensa con la convocatoria a participar en su licitación. Este proceso fue detenido momentáneamente por una acción judicial liderada por organizaciones de los barrios Bellavista, Recoleta y Pedro de Valdivia Norte, iniciativa que se suspendió cuando el proyecto entró al SEIA, y el foco de acción pasó a ser ese. 
FIguRa I | La Región Metropolitana de Santiago y el proyecto Costanera Norte (línea blanca). Las áreas más oscuras son de altos ingresos, mientras las más pálidas son de bajos ingresos y bajas tasas de uso del automóvil

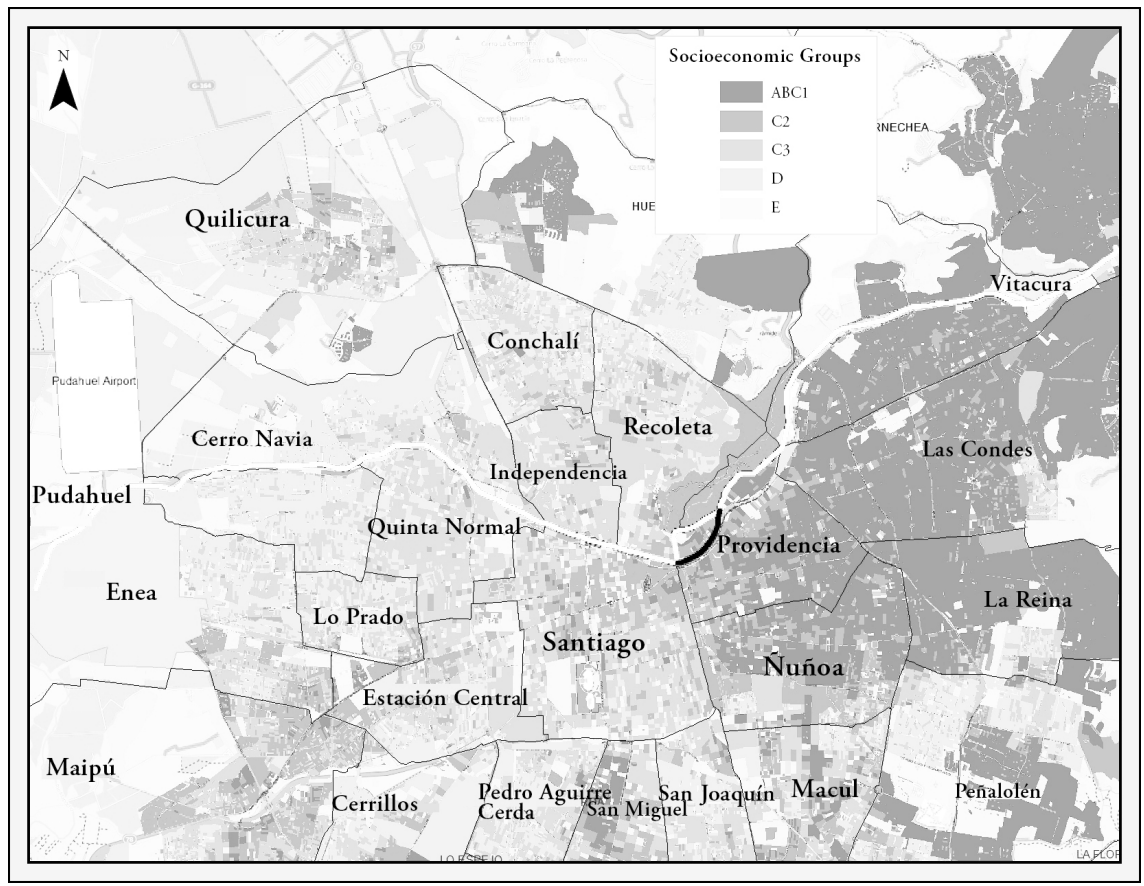

FUENTE SAGARIS, 2012

Hubo intensos debates en el proceso del seia y en los medios, marchas y otras actividades de presión, que se prolongaron durante tres años (1997-2000). La organización concitó enorme apoyo, con notables resultados en cuanto al proyecto mismo y en temas de participación y gestión urbana-regional. Destacó la importancia del proceso de evaluación de impacto ambiental en la evolución del tema y de las organizaciones ciudadanas involucradas.

La respuesta ciudadana: una coalición diversa en el corazón de la ciudad

Veinticinco organizaciones, conformadas por residentes de los barrios Independencia, Bellavista y Pedro de Valdivia Norte, unidos con comerciantes de La Vega Central y Bellavista, se unieron en una coalición opositora: la Coordinadora No a la Costanera Norte. Destacaban sus participantes por su diversidad en términos socioeconómicos, etarios, valóricos, religiosos y políticos.

Una vez que el proyecto entró al SEIA, se hicieron varias exigencias en términos del proceso de participación; fundamentalmente, "igualdad de trato" con el proponente del proyecto y el derecho a acceder directamente a toda instancia involucrada en la toma de decisiones. En general, la voz de la Coordinadora fue escuchada; tanto, que el Consejo Consultivo de la Comisión Regional del Medio Ambiente 
(COREMA), único cuerpo independiente del gobierno, votó dos veces en contra del proyecto, y el gobierno evitó una tercera derrota con una aprobación precipitosa en julio de 1998 (Sepúlveda \& Du Monceau, 1998). En estas circunstancias, la Coordinadora ocupó una estrategia múltiple, recurriendo a la justicia y a los medios de comunicación, a la movilización, la construcción de alianzas, entre otras. En la medida en que avanzaba el debate, surgían voces de expertos que fueron educando y apoyando los argumentos ciudadanos en contra del proyecto. Destacaron urbanistas, incluso premios nacionales, ingenieros de transporte, estudiantes y líderes experimentados del mundo ambiental, particularmente del Observatorio Latinoamericano de Conflictos Ambientales y de la Casa de la Paz.

Comunicacionalmente, la Coordinadora ocupó folletos, pero también nuevas tecnología de comunicación. Se transmitieron las noticias por fax y eventualmente correo electrónico. La vocería fue ejercida por representantes elegidos. Con el apoyo de amistades de habla francesa e inglesa se creó un sitio trilingüe en Geocities, para concitar apoyo en los países de origen de las empresas interesadas en participar en las licitaciones. También hubo un esfuerzo por organizar eventos destinados a sensibilizar a la prensa, revelándose un sesgo fuerte a favor de hablar con los dirigentes del barrio de mayor nivel socioeconómico, Pedro de Valdivia Norte (Sagaris, 2014a).

No obstante lo anterior, los medios masivos nunca fueron la meta principal de la estrategia de comunicaciones. Un análisis reveló que se podía llegar a sectores importantes con medios más directos. Por ejemplo, una mesa informativa en la calle Pío Nono, Bellavista, un domingo podía llegar a 5.000-10.000 personas.

Internamente, las decisiones de la Coordinadora reflejaban los consensos de un consejo compuesto por líderes de las diferentes organizaciones que la conformaban, con voz y voto. Muchas reuniones incluían capacitaciones a cargo de expertos, dirigidas a los vecinos u otros colaboradores. Cada grupo retuvo su identidad y voz propia: incluso cuando se lograron reuniones con las autoridades, iban representantes de todos ellos. Insistían en que hablaran primero los dirigentes, para asegurar que las autoridades respondiesen a temas y planteamientos concretos, y no con generalidades.

Esta estructura horizontal construyó una confianza importante. Si bien en un principio cada grupo defendía sus intereses particulares, con el tiempo estas inquietudes se fueron fusionando en una agenda común, donde cada reivindicación era legítima e importante. En la medida en que la campaña evolucionaba, comentaristas e investigadores notaban que estaba emergiendo un tipo de ciudadanía distinta (Allard, 2003).

Sin embargo, en 2000, después de un año de inactividad, el entonces presidente Eduardo Frei logró encontrar un concesionario dispuesto a asumir el proyecto.

\section{Resultados urbanos y ciudadanos del conflicto Costanera Norte}

El resultado final de la campańa ciudadana contra la Costanera Norte es interesante por sus matices. Como se sintetiza en la tabla 1, no se logró ninguna victoria definitiva. Sin embargo, se pudo influir significativamente en dos planos: el proyecto resultante y el sistema de planificación de la ciudad, particularmente en cuanto al rol de la ciudadanía.

En tres de los cuatro sectores activos que consideraba el proyecto original se logró enterrarlo, dejando intocados los barrios Bellavista, Pedro de Valdivia Norte y 
Recoleta/mercados. Y en Independencia se obtuvieron compensaciones para arrendatarios y allegados, además de propietarios.

Los costos subieron y las promesas de que la inversión la asumiría el privado no se cumplieron, ya que, según las cifras del mop, la autopista le costó directamente al Estado usD 500 millones, fuera de la inversión directa del concesionario.

Al mismo tiempo, se construyó una ciudadanía urbana nueva para la época, independiente de los partidos políticos y capaz de trabajar colaborativamente. Esto se expresó en la organización Ciudad Viva, una instancia de urbanismo ciudadano que en los años 2000 recibió distintos premios que avalaron sus métodos de participación.

Finalmente, un punto de inflexión en el debate público sobre temas de participación se dio primero con el ya mencionado Instructivo Presidencial, que requiere participación en los distintos ministerios, y después en iniciativas importantes como las leyes de Transparencia y de Participación Ciudadana. ${ }^{2}$ No es que este conflicto por sí solo haya impulsado todos estos cambios, pero fue catalizador y parte de una serie de iniciativas ciudadanas que culminaron en ellos, muy significativos no solo para la gestión urbana, sino para la democratización del país.

No queremos darles una lectura excesivamente exitista a estos cambios, ya que en los años siguientes (1997-2007) ni la Coordinadora ni Ciudad Viva tuvieron la capacidad de expandir sus iniciativas más allá del barrio La Chimba. Aunque algunos dirigentes individuales tuvieron un efecto positivo en otros temas, como los planes reguladores de Recoleta y de Providencia, la colectividad no logró su meta de apoyar a otros grupos enfrentados a autopistas. Esta falla, que revela además la resistencia de los políticos y las instituciones a innovaciones favorables al resguardo de los derechos ciudadanos, costó cara a las comunidades que casi simultáneamente enfrentaron otro conflicto por una autopista, el Acceso Sur, también en Santiago, pero esta vez en el extremo sur de la ciudad, donde se concentran sectores de bajos recursos.

2 Referencias a: (i) Instructivo Presidencial n. ${ }^{\circ}$ 030, del 7 de diciembre de 2000, sobre Participación Ciudadana, firmado por Ricardo Lagos Escobar, Presidente de la República, que comienza indicando: "La participación ciudadana es una dimensión fundamental de todo sistema democrático, pues contribuye a que los derechos y deberes institucionalmente establecidos sean efectivamente reconocidos y ejercidos" [http://www.guiadigital.gob.cl/sites/default/files/ instructivopresidencialparticipacion.pdf]; (ii) Ley Núm. 20285 sobre Acceso a la Información Pública, de Ministerio Secretaría General de la Presidencia, publicada el 20 de agosto de 2008, que "regula el principio de transparencia de la función pública, el derecho de acceso a la información de los órganos de la Administración del Estado, los procedimientos para el ejercicio del derecho y para su amparo, y las excepciones a la publicidad de la información" [http://www.leychile. cl/Navegar?idNorma=276363]; y (iii) Ley Núm. 20500, sobre Asociaciones y Participación Ciudadana en la Gestión Pública, de Ministerio Secretaría General de Gobierno, 16 de febrero de 2011, que en su Artículo $1^{\circ}$ señala: "Todas las personas tienen derecho a asociarse libremente para la consecución de fines lícitos. Este derecho comprende la facultad de crear asociaciones que expresen la diversidad de intereses sociales e identidades culturales" [https://www.leychile.cl/ Navegar?idNorma=1023143]. 


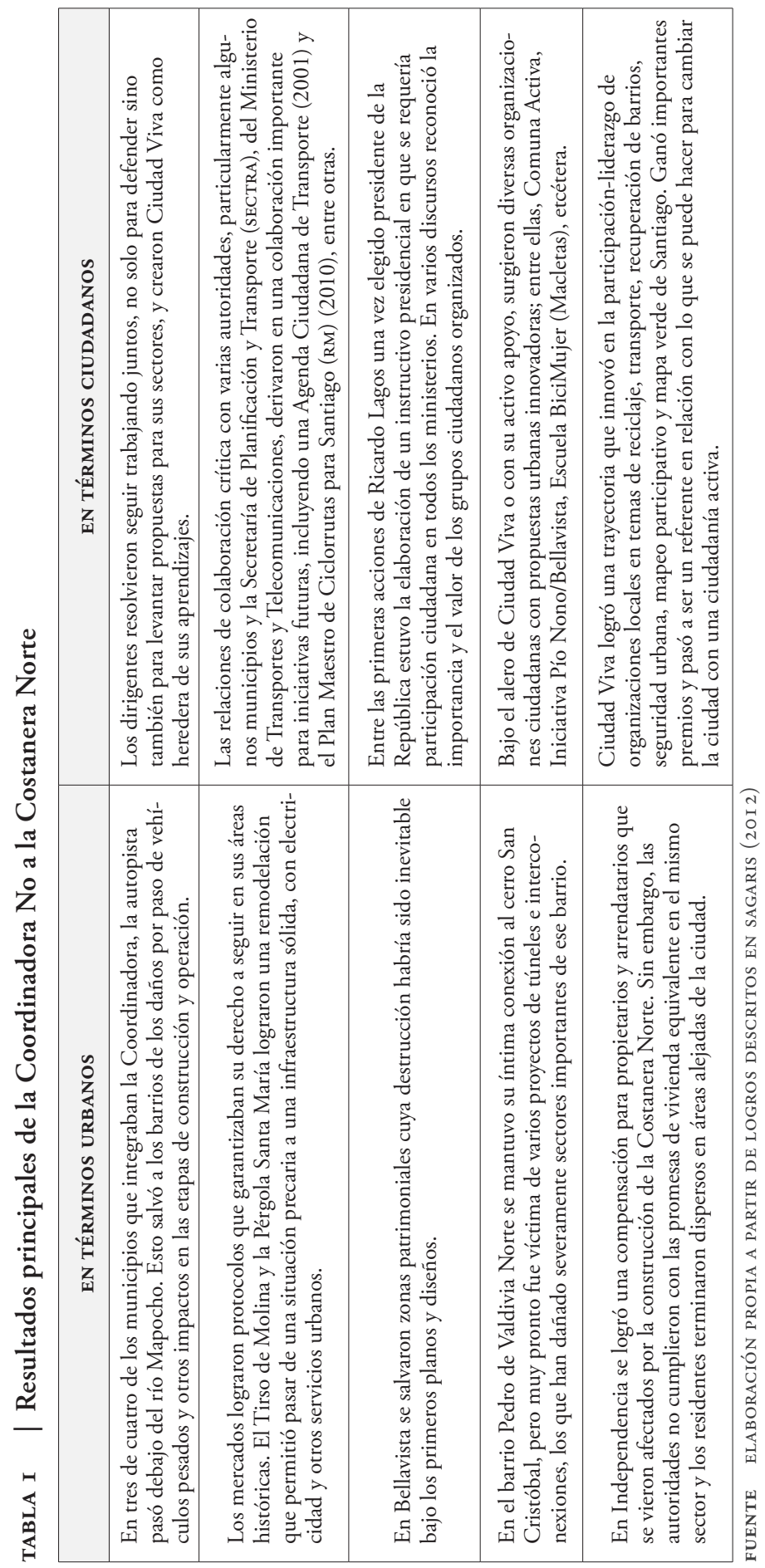




\section{Acceso Sur: derechos ciudadanos denegados}

\section{El proyecto Autopista Acceso Sur}

La Autopista Acceso Sur, según se argumentó, fue diseñada para proveer una alternativa de ingreso a Santiago desde el sur del país, conectando la Ruta 5 con la avenida Américo Vespucio (figura 2). Fue adjudicada en $1998,{ }^{3}$ como parte de la Concesión Internacional de la Autopista Ruta 5 Sur, tramo Santiago-Talca. La empresa que ganó la licitación fue el Consorcio Autopista del Maipo, formado por Cintra, Concesiones de Infraestructuras de Transporte, del Grupo Ferrovial; Golf Center, del Banco Santander; e Infraestructuras 2000, del Grupo Endesa. Esta obra fue ejecutada por Ferrovial-Agromán Internacional y se le otorgó una explotación por un plazo de 25 años, con un costo inicial de USD 300 millones (MOP, 2008).

FIgURA 2 | Área de estudio en el sector sur de Santiago RM y las comunidades específicas que fueron estudiadas

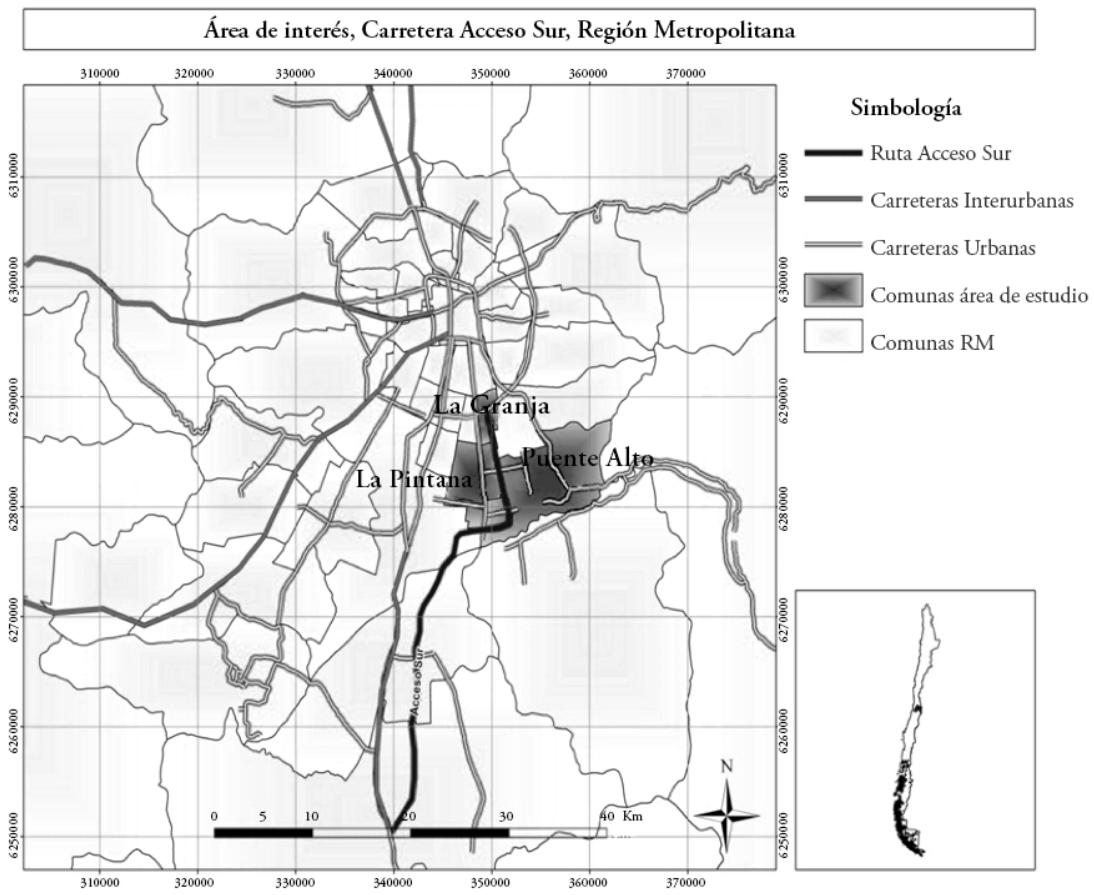

FUENTE LANDON (20I6), P. 63

Por Decreto Supremo Núm. 859 del mop, con fecha 30 de junio de 1998, publicado en el Diario Oficial con fecha 31 de agosto de 1998, se adjudicó el contrato de concesión denominado "Concesión Internacional Ruta 5 Tramo Santiago Talca y Acceso Sur a Santiago", que permite la ejecución, conservación y explotación de las obras públicas fiscales comprendidas entre los kilómetros 29.014 y 219.490 de la Ruta 5 Sur, incluyéndose las obras correspondientes al Acceso Sur a Santiago comprendidas entre los kilómetros 0,000 y 46,586, y las obras correspondientes al bypass Rancagua, comprendidas entre los kilómetros 66.760 y 94.829 . 
La autopista atraviesa comunas del sector sur de la capital con altos niveles de vulnerabilidad y pobreza. En sus 11,2 kilómetros urbanos pasa por las comunas de La Granja, La Pintana y Puente Alto (figura 2). Como cabeza del proyecto, el Mop prometía que este mejoraría la conectividad del sector, al enlazar en su extremo norte con la avenida Américo Vespucio, principal eje vial estructurante del Gran Santiago. Argumentó que esto favorecería el desarrollo de sectores urbanos deprimidos con una población de cerca de 1.550.000 habitantes (INGELOG, 2008), al potenciar las "zonas industriales exclusivas” definidas por el Plan Regulador Metropolitano de Santiago.

El Acceso Sur debió entrar en operación en 2002. Sin embargo, surgieron numerosos problemas de gestión pública, de coordinación sectorial, de diseño y de deficiencias en las normativas de calificación medioambiental. Alargaron el plazo de las obras, surgiendo en este proceso conflictos de distinta índole con las comunidades afectadas. Se inauguró finalmente a inicios de 2010, con ocho ańos de retraso y una serie de acuerdos de compensación aún pendientes. ${ }^{4}$ Es el proyecto vial que ha tomado mayor tiempo en materializarse en el país, con la participación de nueve ministros de Estado pertenecientes a cuatro períodos presidenciales distintos.

\section{La respuesta ciudadana: comunidades alzadas en la periferia}

La participación de las comunidades afectadas comenzó a ser significativa en 2003 y decididamente organizada en 2006. A diferencia de la Coordinadora No a la Costanera Norte, que partió antes de la licitación obligando al gobierno a entrar al SEIA, estos ciudadanos solo supieron sobre el Acceso Sur cuando ya se estaba construyendo. En adelante, se registraron 16 focos de conflictos ciudadanos, los que fueron aplazando la materialización del proyecto.

Originalmente se previó que el 30\% del trazado pasara por sectores habitacionales, considerando una mínima cantidad de expropiaciones, concentradas principalmente en el último tramo de túnel $(2,9 \mathrm{~km})$ y algunos tramos de El Castillo. Sin embargo, la alta intensidad habitacional en algunos de los tramos aledaños a la autopista en las comunas de La Granja y La Pintana hicieron que el proceso de traslado y expropiación fuera muy complejo (Ponce, 2008).

El impacto físico de las obras en el territorio (figura 3), junto con las lógicas desarticuladas de actuación del Estado, motivaron a los habitantes de los barrios más afectados a organizarse, desarrollando diversas manifestaciones orientadas, en una primera fase, a la paralización de las obras; y en una segunda etapa, a la negociación de proyectos de compensación y mitigación con los actores del Estado involucrados. Urbanismo y el Servicio de Vivienda y Urbanismo no habían dado cumplimento a todas las obras y proyectos de compensación comprometidos a los habitantes de los barrios colindantes; entre ellos, la instalación de seńalética en el tramo urbano de la autopista, reconstrucción de áreas verdes, expropiaciones y ampliación de la oferta de transporte público. 
FIGURA 3 | Detalles de la ubicación y fotografías de los impactos de la autopista en las comunidades examinadas

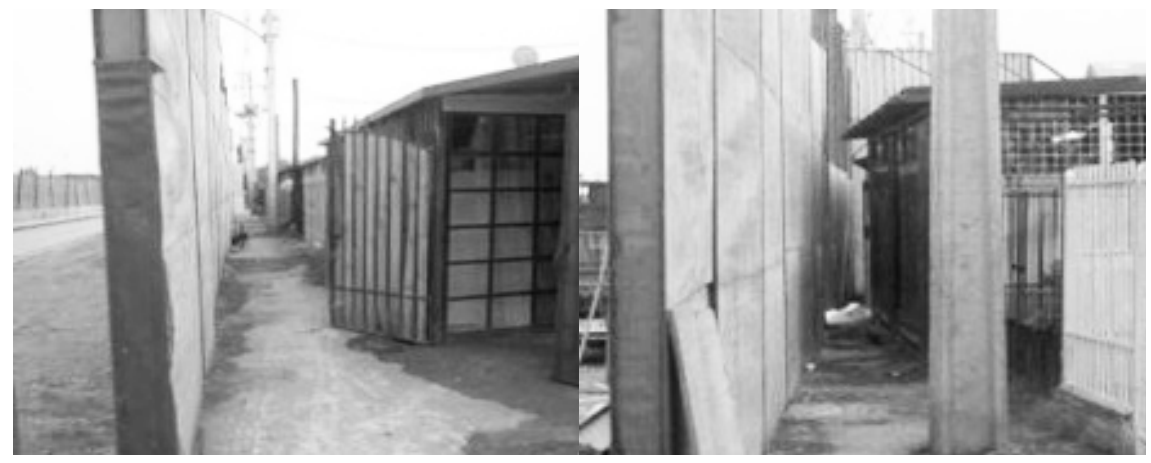

FUENTE WWW.ADACH.CL, VISITADO JULIO $20 \mathrm{I} 2$

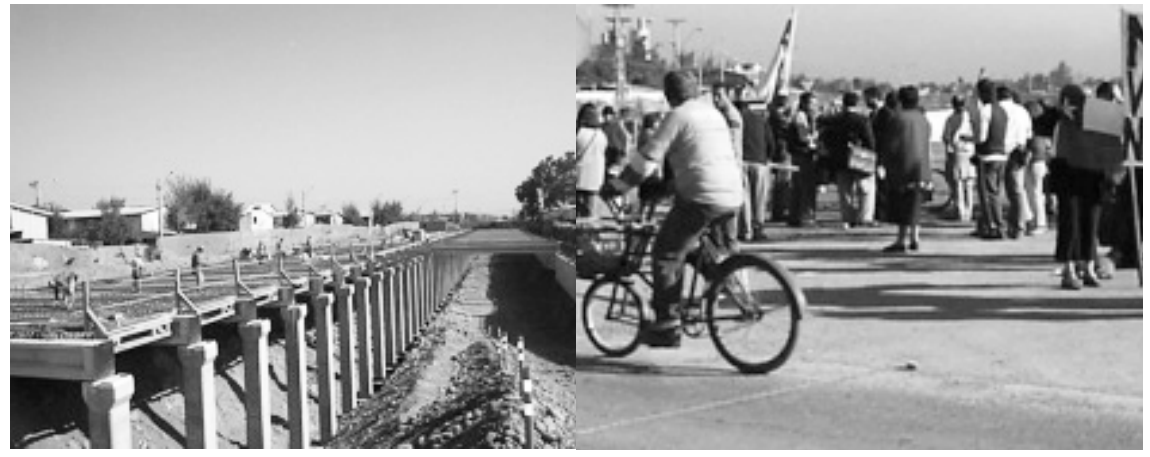

FUENTE ARCHIVO FOTOGRÁFICO MINISTERIO DE OBRAS PÚBLICAS (MOP), 2005

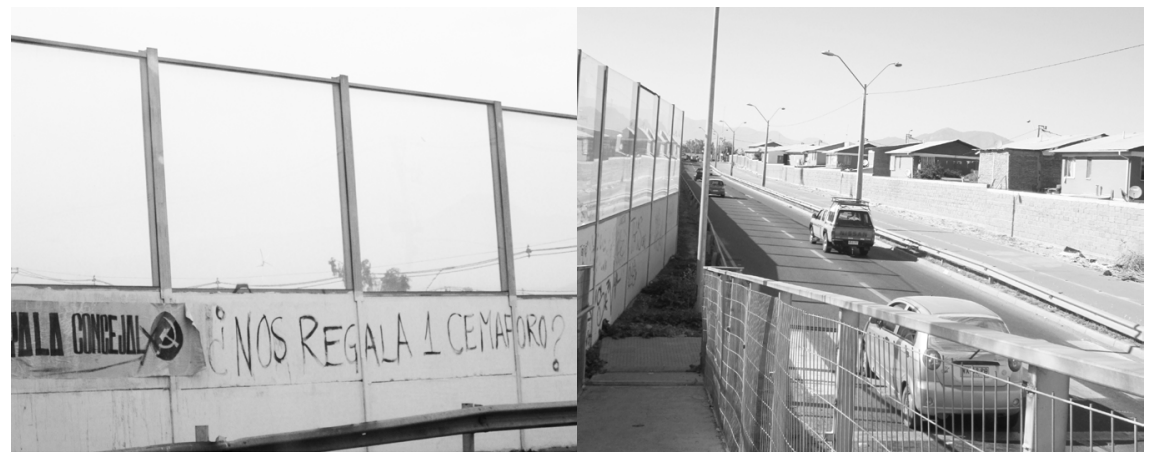

FUENTE ARCHIVO PERSONAL PAULETTE LANDON

En 2006, luego de dos años de paralización de las obras, la comunidad organizada empezó un proceso de negociación informal con las autoridades centrales y locales. Exigieron un trato digno y exteriorizaron el conflicto a través de los medios de comunicación. Frente a estas demandas, el MOp buscó alternativas de solución junto con el Ministerio de Vivienda y Urbanismo (MINvu) y el Servicio de Vivienda y 
Urbanización (sERVIU), dando paso a una negociación formal a través de un Plan de Acción Integral $^{5}$ (MOP, 2010).

Las principales demandas planteadas por los vecinos fueron:

- Cabal cumplimiento de las medidas de mitigación consideradas en las resoluciones de calificación ambiental (RCA).

- Áreas verdes en todos los barrios intervenidos, dado que contaban con amplias aceras, árboles y canales previos a la ejecución de las obras.

- Expropiación de las viviendas de ambos lados de la "caletera" (vía secundaria paralela a la principal) en el tramo urbano, últimos 6 kilómetros con un radio de 200 metros.

FIgURA 4 La Serena (izquierda), Santo Tomás (derecha)

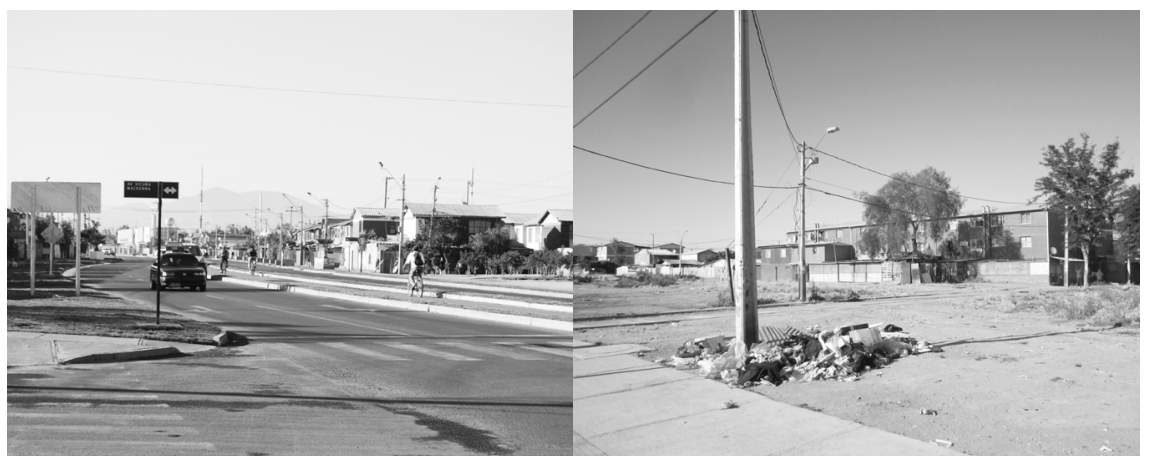

FUENTE ARCHIVO PERSONAL PAULETTE LANDON

En los sectores de La Serena y Santo Tomas (figura 4) se concentró la mayor parte de los conflictos y movilizaciones de los vecinos. En estos últimos 3 kilómetros se construyó la autopista soterrada, literalmente en el borde de las casas de los residentes, a no más de 60 centímetros, situación que se mantuvo por más de dos años.

Sin embargo, el mayor conflicto derivó cuando, en 2008, el Mop cambió el plan de expropiaciones. Entonces se fragmentó la organización social y, por tanto, se otorgaron distintas salidas a las negociaciones. Algunos de los terrenos fueron expropiados, otros propietarios recibieron bonos de arriendo, mejoras en sus viviendas o recursos para la construcción. Algunas organizaciones lograron promesas de parte del Mop de mejoramiento de infraestructuras básicas, sedes comunitarias, salas cuna, techos para canchas deportivas, juegos infantiles, máquinas de ejercicios, pavimentación de pasajes, etcétera. En la práctica, se otorgaron soluciones diferenciadas e

5 Su objetivo central fue atender los impactos que generaría en las comunidades la construcción de esta vía concesionada, desde una dimensión que trasciende las consecuencias objetivas de la instalación de la obra en el territorio, cuestión que se evaluó a través de las resoluciones de calificación ambiental (RCA) y que se ven reflejadas en las medidas complementarias por implementar en la fase de construcción y/u operación del proyecto. Para su implementación se sostuvieron reuniones periódicas entre los municipios de La Granja y La Pintana, y el Comité Ecológico, Comité Ilusiones, Juntas de Vecinos y nuevas organizaciones informales de los vecinos. 
inequitativas. El mayor éxito de las negociaciones dependió de la capacidad política de los dirigentes.

Uno de los pocos logros colectivos fue que se incluyera en este tramo de 2,9 kilómetros tunelizados, una ciclovía por el centro de la "caletera", la mejora de algunas infraestructuras deportivas en su borde, y luminarias. Sin embargo, los vecinos todavía esperan que se materialice la construcción del parque La Serena, proyecto que aglutinó a todas las organizaciones y que permitió destrabar el conflicto en 2008 y reanudar las obras.

En el sector de El Castillo, la organización de los vecinos fue más articulada y permanente, particularmente el Comité Ilusiones, la única agrupación que continúa vigente y que todavía exige el cumplimento de los acuerdos de compensación. En este tramo se vivenciaron dos importantes focos de conflicto, que paralizaron las obras por otros dos ańos. El primero se dio en la intersección de las avenidas La Serena y Batallón Chacabuco, centro neurálgico del barrio, que conecta el ingreso del transporte público por el eje vial principal, Batallón Chacabuco. Las obras complementarias construidas en este tramo, no previstas en el diseńo, como los colectores y sus respectivos cambios de servicio, generaron prolongados cierres de calles, por los trabajos de restauración de las roturas de los ductos y cañerías. El segundo conflicto data de inicios de 2001, cuando el proyecto de licitación ya estaba en marcha y se construyó un conjunto de cerca de 200 viviendas sociales en la franja fiscal adyacente a donde se ejecutarían las obras (Ponce, 2008).

La mayor magnitud de los impactos ambientales se registró en las poblaciones que residían en los barrios aledaños al sector del túnel soterrado, Santo Tomas y La Serena. Las obras se instalaron a un metro de las rejas de las casas, separando con mallas algunos tramos, realizando cortes de calles y accesos para las faenas de excavación. Esta situación expuso a la población residente a ruidos molestos, polución e inundaciones, y dificultó el suministro de servicios básicos en los barrios contiguos (Comisión Arbitral, 2010). En algunos sectores tuvieron que soportar estas condiciones por más de dos años, con serios problemas de salud, acceso y circulación intra y extra barrial.

A diferencia del caso de Costanera Norte, en el Acceso Sur los afectados contaron con un limitado apoyo de la ciudadanía en general y una baja cobertura en los medios. Tampoco activaron una campaña comunicacional, más allá de depender de los medios masivos.

Las autoridades locales se centraron en las negociaciones a baja escala en torno a obras de mitigación asociadas, no necesariamente en los territorios directamente afectados. Tal como ocurrió con la Costanera Norte, el Mop aplicó la estrategia de neutralizar el cuestionamiento de las organizaciones comunitarias y municipalidades. Y sin el proceso del seia que dio espacio a la participación de la Coordinadora, las organizaciones asociadas al Acceso Sur no se unieron, de forma que esta estrategia no se transparentó.

En el caso de los conflictos entre grupos ciudadanos y el Mop, el gobierno utilizó tres tácticas: redefinir la autopista como "interurbana” para no considerar las comunidades impactadas; evadir la obligación legal del SEIA; e imponer condiciones de expropiación extremadamente desventajosas. 
En primer lugar, la insistencia en la condición interurbana del Acceso Sur negó la existencia de las comunidades aledańas y, por lo tanto, sus posibilidades de ser tratadas dignamente. Por esta razón, la autopista no incluyó semáforos en cruces y accesos, señalética local y pasos peatonales. Esto condicionó las posibilidades de conectividad y seguridad de los habitantes de los barrios aledańos a este proyecto vial, y sigue produciendo altos niveles de aislación física y segregación sociopolítica.

En segundo lugar, la inexistencia de una evaluación ambiental del proyecto para dar inicio a las obras eliminó la posibilidad de una participación ciudadana formal, haciendo evidente que el MOP no consideró las variables relacionadas con los aspectos sociales, económicos y culturales de la población contigua a las obras. Dicha consideración habría permitido anticipar soluciones frente a las reivindicaciones legítimas, que llevaron a duplicar los años y costos de construcción. ${ }^{6}$

En tercer lugar, en un comienzo, el Mop supuso que el proceso de expropiación no sería un obstáculo relevante para la construcción de las obras, ya que su política de realizar negociaciones individuales y prácticamente invisibles había dado buenos resultados en otros sectores. En el caso de la Costanera Norte, sin embargo, las organizaciones de arrendatarios, propietarios y allegados habían logrado compensaciones significativas para sus viviendas y hubo algunos contactos entre sus dirigentes y las comunidades del Acceso Sur.

Por otra parte, la alta rotación de ministros de Obras Públicas se tradujo en decisiones que se alejaron del proyecto inicial, cambiando los acuerdos establecidos con las comunidades locales (Landon, 2013). Los efectos asociados a estos cambios le ocasionaron al gobierno serios problemas con la concesionaria, producto del retraso de las obras y aumento de los costos.

Con base en la Ley 19.300, sobre Bases Generales del Medio Ambiente, ${ }^{7}$ los actores locales exigieron que el proyecto Acceso Sur se sometiera a RCA en dos ocasiones $(1999,2002)$. Se realizó un último "ajuste" en 2005. El reconocimiento del impacto ambiental no previsto por parte del MOp derivó en dos acciones concretas:

- El pago de un bono de compensación de \$7.200.000 a la población que residía en las viviendas aledańas al sector del túnel soterrado, en avenida La Serena entre Vicuña Mackenna y General Arriagada (La Granja y La Pintana), y en el pasaje El Piano, entre calles General Arriagada y San Miguel (La Pintana), a través de un convenio de compensación firmado con cada vecino en noviembre de 2005.

- Una serie de medidas ambientales adicionales, tanto para la etapa de construcción como de operación, con el fin de mitigar y compensar el impacto que tendrían, en la calidad de vida de la población residente, situaciones ambientales que fueron incorporadas en una nueva resolución de calificación ambiental

6 A la fecha no se ha encontrado un documento que entregue información sobre los costos finales de este proyecto. En la entrevista realizada a un exdirector de Vialidad del Mop, este indicó que el costo final habría superado con creces el presupuesto inicial, si se consideran las obras complementarias no previstas; entre ellas, túnel soterrado, colectores, etcétera.

7 Con base en la legislación ambiental, se solicitó la Resolución de Calidad Ambiental (RCA) del proyecto en el ańo 1999, y posteriormente se hicieron ajustes en los años 2002 y 2005. En documento Comisión Arbitral, 2010, p. 15. 
emitida por la Comisión Regional del Medio Ambiente (corema) de la Región Metropolitana, la No 502/05, en 2005 (Comisión Arbitral, 2010).

Estas medidas no tuvieron el éxito esperado y se estableció un precedente que continúa hasta el día hoy: las autopistas urbanas no están sujetas a estudios a fondo, a participación ciudadana, ni a los otros resguardos que son parte integral de un sistema efectivo de evaluación.

\section{Resultados urbanos y ciudadanos del conflicto Acceso Sur}

Dada la complejidad del caso y sus aristas, identificamos dos planos de resultados: urbano e institucional.

\section{A nivel urbano: la ciudadanía sin garantías}

La Autopista Acceso Sur ha sido una de las mayores inversiones en infraestructura en el territorio sur de Santiago (Red Popular Enrique Torres [RPET], 2009), en beneficio principalmente de gente que no vive ni trabaja allí. Los voceros del gobierno prometían que el proyecto aportaría a una mayor integración de las personas que habitan en los barrios aledańos. La experiencia desmiente estas promesas, ya que la carretera reforzó la desigualdad y la exclusión social de estas comunidades. El diseńo de lo que se argumentó era una política de renovación urbana, no consideró la complejidad política, administrativa y territorial del tejido urbano intervenido. Tampoco lo hizo con las necesidades de los vecinos afectados, personas vulnerables y excluidas. Esta nueva vía no fue diseñada para ellos, que no pueden pagar por su uso.

La exclusión de la población se ve reflejada también en el mínimo cuidado en la conexión de la autopista con las vías estructurantes de los barrios afectados, que ha generado un borde que se transforma en una barrera para sus habitantes. La intervención vial constituye una de varias medidas de planificación que, sin consulta ni participación, han devenido en procesos que han incrementado el aislamiento urbano. Esto se expresa en cambios en los trayectos y recorridos cotidianos de los habitantes afectados, que en la mayoría de los casos implican un aumento de tiempo de traslado y de los costos de transporte.

Otras externalidades negativas incluyen la degradación de las zonas más inmediatas al proyecto, el efecto barrera en las zonas donde se implanta, y el efecto túnel, que lleva a una pérdida de valor en las zonas adyacentes que no tienen comunicación con la infraestructura construida (Figueroa, 2013). En especial se observa esta situación en los barrios Bajos de Mena y El Castillo. Además, existen otros impactos indirectos, como la concentración de contaminación (microbasurales en los bordes de la "caletera"), los riesgos de accidentes y la congestión. En el caso de los barrios La Serena y Santo Tomás, se observa una importante pérdida de áreas verdes en las aceras debido a la construcción en túnel.

\section{A nivel ciudadano e institucional}

Sin transparentar el proyecto en el momento de su planificación y antes de su implementación, en el caso de Acceso Sur ocurrieron diversas situaciones que no solo muestran la falta de control público sobre estas políticas urbanas, sino también 
la total vulnerabilidad de la población en cuanto al respeto de los derechos ciudadanos. Aquí destacamos los principales ejemplos.

- Cruces institucionales y desarticulación entre organismos estatales. En un mismo territorio se producen intervenciones de carácter público incompatibles y contradictorias. Así, en una franja de tierra fiscal destinada a la carretera, y cuando el proyecto de autopista del MOp ya estaba en licitación, el MINVu construyó viviendas sociales, que luego de cuatro ańos debieron ser demolidas y expropiadas. Esta situación evidencia la falta de comunicación entre entidades públicas, privadas $^{8}$ y la sociedad civil. Así, viviendas esenciales para familias de bajos ingresos fueron sacrificadas para la automovilidad de hogares de altos ingresos.

- Ahorros para la empresa. La insistencia del mop en definir el proyecto como interurbano significó ahorros para la empresa concesionaria. Gracias a esto, se invirtió menos en señalética, pasarelas y otras facilidades para los habitantes y usuarios de estos sectores. Aquí se identifica una contradicción difícilmente aceptable en una sociedad democrática, asociada a la relación del gobierno y los agentes de mercado, quienes asumen tareas de construcción directa de bienes "públicos", con fuerte énfasis en el derecho de movilidad de quienes tienen capacidad de pago y hacen uso del auto particular, en detrimento de las movilidades locales y vecinales.

- Falta de articulación entre la autoridad central y la autoridad local. La marginal participación de los municipios en el conflicto evidencia el carácter centralista y hasta clientelista del proceso. Podemos identificar una participación tangencial de los municipios de La Granja y La Pintana, centrados en negociar beneficios para sus respectivas comunas con el MOP, MINVU y SERVIU, con el objeto de dar cumplimiento a diversos proyectos locales y territoriales de alto costo económico. Dichas negociaciones no necesariamente formaron parte de las compensaciones solicitadas por los habitantes de los barrios afectados (Landon \& Rodríguez, en De la Fuente \& Mlynarz, 2013). En este sentido, identificamos el carácter electoralista con que la autoridad local asumió la negociación por recursos para mitigación.

\section{Conclusiones: ¿quién garantiza los derechos ciudadanos?}

Como evidencian estos casos, la segmentación y segregación territorial que caracteriza a Santiago está siendo agudizada por megaintervenciones urbanas como el Acceso Sur y la Costanera Norte, cuyos procesos de diseño e implementación resultan poco abiertos a la participación ciudadana, en particular a quienes no son usuarios del automóvil. El hecho de que el mop haya eliminado (o intentado eliminar) el cumplimiento del sEIA para estos proyectos, y con eso la posibilidad de una ciudadanía participativa en dichos procesos, habla muy mal de la institucionalidad del país. Si el mismo gobierno no respeta las normas, ¿quién más lo va a hacer?

El Mop y Sociedad Concesionaria del Maipo se enfrentaron en el año 2010 a un litigio legal, con una demanda presentada por ambos agentes a la Comisión de Conciliación y Arbitral, la que se resolvió a favor del MOP en 2014. Véase en http://www.newprocess.cl/noticias/eximen-al-mop-depagar-multa-de-\$40-mil-millones-6080.php, visitado el 9 de septiembre de 2016. 
Es importante, por lo tanto, subrayar la importancia de la evaluación de impacto ambiental (y social), con su obligación de participación ciudadana, como un componente esencial para tomar decisiones justas y transparentes en la planificación de megaproyectos en la ciudad. Como hemos visto, mientras la Coordinadora tuvo el tiempo del SEIA para organizarse y construir relaciones con diversas organizaciones, los grupos del Acceso Sur amanecieron una mańana con la autopista literalmente golpeando sus puertas. Respondieron con todas las herramientas que tuvieron disponibles, pero al poder reaccionar solo una vez que la construcción había comenzado, sus opciones fueron pocas, creándose un conflicto muy dañino para la comunidad y la confianza ciudadana-gobierno.

Para la Coordinadora, su diversidad le facilitó el acceso a conocimientos y personas influyentes, o sea, capital social de puente. A diferencia de las comunidades nuevas del Acceso Sur, muchas de ellas producto de los traumas de desplazamiento producidos por las políticas segregadoras de la dictadura, los grupos de la Coordinadora gozaban de cierta historia común que permitía una identidad compartida y reconocible.

Estos casos revelan que el Estado es reacio a considerar a los ciudadanos como actores relevantes al momento de planificar nuestras ciudades. Los conflictos actuales de comunidades diversas (Peñalolén, La Reina, La Florida, Macul, entre otros) contra autopistas indican que las condiciones no han cambiado sustancialmente. Es urgente reconocer y responder adecuadamente a las dinámicas sociales que producen las intervenciones viales urbanas, así como a sus consecuencias en la vida cotidiana de los habitantes de barrios que sufren una mayor exclusión socioespacial en la ciudad.

En ambos casos, pero particularmente en el Acceso Sur, se debilitó la idea de la ciudad como espacio social y se aprovechó la reclusión de los habitantes en barrios ya socialmente estratificados para excluirlos aún más de decisiones vitales para su bienestar. Podemos constatar que obras que se presentaron como beneficios metropolitanos, produjeron costos diferenciados, concentrando las externalidades negativas en la escala local, o sea, subsidiando a los más ricos al mismo tiempo que se penaliza a los más pobres, empeorando sustancialmente su calidad de vida y su derecho a ejercer la ciudadanía.

Lejos de velar para que estos grupos ciudadanos pudiesen ejercer sus derechos de participar en condiciones de igualdad, al adoptar la estrategia de evitar el proceso de evaluación de impacto ambiental, el Ministerio de Obras Públicas aprovechó la desigualdad de una manera que hizo más vulnerable a ciertos sectores de la población. Y lo sigue haciendo, ya que, después de la Costanera Norte, las autopistas urbanas no se han sometido a un estudio de impacto ambiental, con su respectiva participación ciudadana. Es necesario, sin embargo, subrayar importantes diferencias en el actuar de las instancias del Estado. Al nivel local, varias municipalidades han brillado con innovaciones importantes, como El Bosque en sus colaboraciones con los recicladores, La Pintana con los pueblos originales o Lo Prado, Santiago y Providencia en temas de transporte.

Similarmente, al nivel nacional, la búsqueda de formas de enriquecer la participación ciudadana, como el proceso liderado por la Comisión Pro Movilidad en 2015, o el proceso relacionado con Transantiago (Nueva Alameda), en 2016, demuestra cierta voluntad y posibilidades de construir nuevas relaciones entre el 
sistema de planificación, la política (el poder) y la ciudadanía. El Mop, por lo visto, está quedando atrás, constituyéndose en una especie de poder fáctico del urbanismo, al implementar megaproyectos como autopistas y otros, sin cumplir con las exigencias de la ciudadanía y de la modernidad -y tampoco de la legislación actualen cuanto a la participación y transparencia.

Estos dos casos nos obligan a interrogar los conceptos de "participación” y "ciudadanía” en el Chile de hoy, por lo menos en relación con ciertas instancias estatales. ¿En qué consiste la participación ciudadana en una democracia? ¿Cómo se garantiza el derecho humano a la participación? Para ambos casos, se verifica una ausencia de compromiso con la participación comunitaria prevista en la institucionalidad vigente, lo que constituye un fuerte mecanismo de exclusión. Se pierde una serie de oportunidades y posibilidades, ya que, según se indica en el Manual de participación ciudadana en el proceso de evaluación de impacto ambiental (Casa de la Paz, Participa, Practica, 1995), en la participación temprana de las comunidades, y particularmente si estas se involucran en los procesos de evaluación de impacto ambiental, es posible prevenir potenciales conflictos, evitando consecuencias negativas en una etapa en que aún se pueden realizar modificaciones al proyecto, mitigando eventuales daños ambientales desde el inicio e incluyendo aspectos no considerados previamente por el proponente o autoridad pública y ambiental.

Esta realidad plantea la necesidad urgente de mejorar el control social y político del sistema de concesiones y del MOP, asegurando una mayor transparencia y una participación adecuada en todo el proceso. Esta última debe partir en la etapa de análisis de los problemas de conectividad e integración social, pasando por las alternativas examinadas y, finalmente, en el caso de los proyectos escogidos, por el diseño del proceso y de los contratos involucrados, garantizando así condiciones técnicas, medioambientales y de participación social.

Estos casos también demuestran que, tal como dice Dahl (1992), la ciudadanía es competente en cuanto a ejercer sus derechos. Reclama un Estado democrático capaz de resguardar su pleno ejercicio, sin discriminaciones categóricas, como las que se evidencian aquí. Como se resume al principio de este artículo, la experiencia internacional demuestra que las sociedades capaces de acoger los aprendizajes de estos conflictos urbanos desarrollan niveles de ciudadanía más competentes, al mismo tiempo que avanzan hacia políticas urbanas más sustentables, en lo ambiental y en lo económico, pero por sobre todo en lo humano.

\section{Referencias bibliográficas}

Allard, P. (2003). The tough road to a living city. ReVista. Harvard Review of Latin America (Winter 2003). Cityscapes. Latinamerica and beyond, 31-33. http://revista.drclas. harvard.edu/book/tough-road-living-city

Ascher, F. (2005). Le sens du mouvement: modernités et mobilités. L'essentiel des comunications. París: Éditions Belin. 
Avritzer, L. (2002). Democracy and the public space in Latin America. Princeton: Princeton University Press, Kindle Edition.

Barber, B. R. (1998). A place for us: How to make society civil and democracy strong. Nueva York: Hill and Wang.

Beckmann, J. (2001). Automobility - A social problem and theoretical concept. Environment and Planning D: Society and Space, 19(5), 593-607. doi: 10.1068/d222t

Booher, D. E. \& Innes, J. E. (2002). Network power in collaborative planning. Journal of Planning Education and Research, 21(3), 221-236. doi: 10.1177/0739456x0202100301

Borja, J. (2002). Ciudadanía y globalización. Serie Documento, 29. Buenos Aires: Centro de Documentación en Políticas Sociales, Secretaría de Desarrollo Social. http:// municipios.unq.edu.ar/modules/mislibros/archivos/doc29\%20.pdf

Bradford, H. (2011, 24 de mayo). 10 countries with the worst income inequality: oECD. Huffington Post. http://www.huffingtonpost.com/2011/05/23/10-countries-withworst-income-inequality_n_865869.html\#s278244title=1_Chile

Brahm, A. (2008). Autopistas urbanas: Santiago, Chile. Arq, (60), 28-39. http://dx.doi. org/10.4067/S0717-69962005006000005

Byrne, D. S. (2001). Understanding the urban. Houndmills, Basingstoke, Ru/Nueva York: Palgrave.

Casa de la Paz, Participa, Practica (1995). Manual de participación ciudadana en el proceso de evaluación de impacto ambiental. Santiago, Chile: Casa de la Paz, Participa, Práctica.

Comisión de Conciliación y Arbitral Ruta 5 Sur, tramo Santiago - Talca y Acceso Sur a Santiago. Documento con fecha 12 de octubre de 2010.

Dahl, R. (1992). The problem of civic competence. Journal of Democracy, 3(4), 45-59. doi: $10.1353 /$ jod.1992.0048

De la Fuente, G. \& Mlynarz, D. (Eds.). (2013). El pueblo unido... mitos y realidades sobre la participación ciudadana en Chile. Santiago, Chile: Ediciones Universidad Alberto Hurtado.

Délano, M. \& Traslaviña, H. (1989). La herencia de los Chicago boys. Santiago, Chile: Ornitorrinco.

Evans, P. B. (Ed.). (2002). Livable cities?: Urban struggles for livelihood and sustainability. Berkeley, Ca: University of California Press.

Fainstein, S. S. (2010). The just city. Ithaca/Londres: Cornell University Press.

Figueroa, O. (2013). Infraestructuras de transporte terrestre, ciudad y movilidad en América Latina. En J. Erazo Espinoza (Coord.), Infraestructuras urbanas en América Latina: gestión y construcción de servicios y obras públicas (pp. 241-264). Quito: Instituto de Altos Estudios Nacionales (IAEN). https://works.bepress.com/jaime_erazoespinosa/10/

Friedmann, J. (1992). Empowerment: The politics of alternative development. Cambridge, MA: Blackwell.

Friedmann, J. (2000). The good city: In defense of utopian thinking. International Journal of Urban and Regional Research, 24(2), 460-472. doi: 10.1111/1468-2427.00258

Gastil, J. (2000). Is face-to-face citizen deliberation a luxury or a necessity? Political Communication, 17(4), 357-361. http://dx.doi.org/10.1080/10584600050178960

Harvey, D. (2012). Rebel cities: From the right to the city to the urban revolution. Nueva York: Verso. 
Hasan, A. (2005). The political and institutional blockages to good governance: The case of the Lyari expressway in Karachi. Environment and Urbanization, 17(2), 127-141. doi: $10.1177 / 095624780501700210$

Hovey, B. (1998). Building the city, structuring change: Portland's implicit utopian project. Utopian Studies, 9(1), 68-79.

Instructivo Presidencial Núm. 030, del 7 de diciembre de 2000, sobre Participación Ciudadana, firmado por Ricardo Lagos Escobar, Presidente de la República http://www.guiadigital. gob.cl/sites/default/files/instructivopresidencialparticipacion.pdf

Ingelog (2008). Informe sobre Proyecto Autopista Acceso Sur a Santiago. http://www.aic.cl/ wp-content/themes/default/pdf-empresas/Ingelog\%20S.A..pdf

Jacobs, J. (1961). The death and life of great American cities. Nueva York: Vintage Books (V-241).

Ladd, B. (2008). Autophobia: Love and hate in the automotive age. Chicago, IL: University of Chicago Press.

Landon, P. \& Rodríguez-Milhomens, B. (2013). El derecho a la movilidad espacial y a la participación en la ciudad. En G. de la Fuente \& D. Mlynarz, El pueblo unido... Mitos y realidades sobre la participación ciudadana en Chile (pp.181-210). Santiago, Chile: Ediciones Universidad Alberto Hurtado.

Landon, P. (2013). Movilidad cotidiana e infraestructura vial: nuevos desafíos urbanos para la inclusión social en la ciudad. El caso de la Autopista Acceso a Santiago. Revista de Trabajo Social [Pontificia Universidad Católica de Chile] (84), 31-45.

Landon, P. (2016). Zona Sur: barrios, infraestructura y movilidad cotidiana. Documento final tesis doctoral en Arquitectura y Estudios Urbanos, Facultad de Arquitectura, Diseño y Estudios Urbanos, Pontificia Universidad Católica de Chile.

Latinobarómetro. (2004). Informe - Resumen Latinobarómetro 2004. Una década de mediciones. Santiago, Chile: Corporación Latinobarómetro. http://www.latinobarometro.org/ latContents.jsp

Lefebvre, H. \& Goonewardena, K. (2008). Space, difference, everyday life: Reading Henri Lefebvre. Nueva York: Routledge.

Ley Núm. 20285, sobre Acceso a la Información Pública, de Ministerio Secretaría General de la Presidencia, 20 de agosto de 2008. http://www.leychile.cl/Navegar?idNorma=276363

Ley Núm. 20500, sobre Asociaciones y Participación Ciudadana en la Gestión Pública, de Ministerio Secretaría General de Gobierno, 16 de febrero de 2011, https://www. leychile.cl/Navegar?idNorma $=1023143$

Mansbridge, J. (1983). Beyond adversary democracy. Chicago, IL: University of Chicago Press.

Matamala, D. (2015). Poderoso caballero. Santiago, Chile: Ediciones Universidad Diego Portales.

Mohl, R. (2004). Stop the road: Freeway revolts in American cities. Journal of Urban History, 30(5), 674-706. doi: 10.1177/0096144204265180

Mohl, R. (2008). The interstates and the cities: The us Department of Transportation and the freeway revolt 1966-1973. Journal of Policy History, 20(2), 193-226. http://dx.doi. org/10.1353/jph.0.0014

Ministerio de Obras Públicas (мор). (2008). Descripción del Proyecto Ruta 5, Tramo Santiago-Talca y Acceso Sur a Santiago. http://www.concesiones.cl/proyectos/Paginas/ detalleExplotacion.aspx?item $=36$ 
Ministerio de Obras Públicas (MOP). (2010). Decreto 396 - Aprueba convenio ad referéndum n. 3 del contrato de concesión de la obra pública fiscal denominada 'concesión internacional ruta 5, tramo Santiago-Talca y Acceso Sur a Santiago’. http://legislacionoficial.vlex.cl/vid/convenio-concesion-talca-248232562

Orlikowski, W. J. \& Baroudi, J. J. (1991). Studying information technology in organizations: research approaches and assumptions. Information Systems Research (2), 1-28. http:// dx.doi.org/10.1287/isre.2.1.1

Oxhorn, P. (2009). Citizenship as Consumption or Citizenship as Agency Comparing Democratizing Reforms in Bolivia and Brazil. Annual meeting of the American Political Science Association. Toronto, Canadá.

Oxhorn, P. (1995). Organizing civil society: the popular sectors and the struggle for democracy in Chile. University Park, PA: Pennsylvania State University Press.

Pateman, C. (1974). Participation and democratic theory. Londres: Cambridge University Press.

Ponce, P. (2008). Acceso Sur Santiago: una autopista sin salida. Plataforma Urbana (22 de febrero de 2008) [En línea]. http://www.plataformaurbana.cl/archive/2008/02/22/ acceso-sur-santiago-una-autopista-sin-salida/.

Programa de Naciones Unidas para el Desarrollo (pNud). (2004). Desarrollo humano en Chile. El poder: ¿para qué y para quién? Santiago, Chile: PNuD. http://desarrollohumano.cl/ idh/informes/2004-el-poder-para-que-y-para-quien/

Putnam, R. (2000). Bowling alone. The collapse and revival of American Community. Nueva York: Simon and Schuster.

Reason, P. \& Bradbury, H. (2008). The Sage handbook of action research: participative inquiry and practice. Concise Paperback Edition ( $2^{\mathrm{a}} \mathrm{ed}$.). Londred: SAGE.

Red Popular Enrique Torres (RPET). 2009. Chile. Carretera acceso sur: la autopista de la injusticia [En línea] http://accionpropagandanoticias.blogspot.com/2009/09/chilecarretera-acceso-sur-santiago-la.html [Acceso 02 de noviembre de 2010].

Reyes, P. \& Hernández, A. (2008). El estudio de caso en el contexto de la crisis de la modernidad. Cinta Moebio, (32), 70-89. doi: 10.4067/S0717-554X2008000200001

Sabatini, F., Wormald, G., Sierralta, C. \& Peters, P. A. (2009). Residential segregation in Santiago: Scale-related effects and trends, 1992-2002. En B. R. Roberts \& R. H. Wilson (Eds.), Urban segregation and governance in the Americas (pp. 121-144). Nueva York: Palgrave Macmillan.

Sagaris, L. (2012). Citizens, complexity and the city. Lessons from citizen participation in urban (transport) planning in Santiago, Chile 1990-2012. Tesis doctoral, Department of Geography and Planning, University of Toronto, Toronto. http://www.brt.cl/citizenscomplexity-and-the-city-lessons-from-citizen-participation-in-urban-transportplanning-in-santiago-chile-1997-2012/

Sagaris, L. (2014a). Citizen participation for sustainable transport: The case of "Living City" in Santiago, Chile (1997-2012). Journal of Transport Geography, 41 (dic. 2014), 74-83. http://dx.doi.org/10.1016/j.jtrangeo.2014.08.011

Sagaris, L. (2014b). Citizens' anti-highway revolt in post-Pinochet Chile: Catalyzing innovation in transport planning. Planning Practice \& Research 29(3), 268-280. http://dx.doi.org /10.1080/02697459.2014.929840 
Sepúlveda, C. \& I. du Monceau (1998). Caso Proyecto Costanera Norte: el comportamiento del SEIA ante una comunidad que se toma la participación en serio. Ambiente y Desarrollo, 14(3), 23-33. http://www.cipma.cl/web/200.75.6.169/RAD/1998/3_Sepulveda.pdf

Sheller, M. \& Urry, J. (2000). The city and the car. International Journal of Urban and Regional Research, 24(4), 737-757. doi: 10.1111/1468-2427.00276

Sorensen, A. \& Sagaris, L. (2010). From participation to the right to the city: Democratic place management at the neighbourhood scale in comparative perspective. Planning, Practice \& Research, 25(3), 297-316. http://dx.doi.org/10.1080/02697459.2010.503424

Susskind, L. \& Elliott, M. (1983). Paternalism, conflict, and coproduction: learning from citizen action and citizen participation in Western Europe. Nueva York: Plenum Press.

Taylor, L. (2004). Client-ship and citizenship in Latin America. Bulletin of Latin American Research, 23(2), 213-227. doi: 10.1111/j.1470-9856.2004.00105.x

Thomson, K. (2001). From neighborhood to nation the democratic foundations of civil society. Hanover/Londres: University Press of New England.

Tilly, C. (2007). Democracy. Cambridge, Ru: Cambridge University Press. http://dx.doi. org/10.1017/CBO9780511804922

Wagenbuur, M. (2009). How the Dutch got their cyclepaths. Post en blog Bicycle Dutch, https:// bicycledutch.wordpress.com/about / con enlace a http://www.youtube.com/markenlei

Zukin, S. (1995). Whose culture? Whose city? The cultures of cities. Cambridge, Ma: Blackwell Publishing. 
